\title{
Knowledge Management System for Railway Supply Chain Perspective
}

\author{
Mailasan Jayakrishnan', Abdul Karim Mohamad', Mokhtar Mohd Yusof ${ }^{2}$ \\ ${ }^{1}$ Centre for Advanced Computing Technology, Faculty of Information \& Communication Technology, Universiti \\ Teknikal Malaysia Melaka, Hang Tuah Jaya, 76100, Durian Tunggal, Melaka, Malaysia \\ ${ }^{2}$ Faculty of Computer and Information Technology, Al-Madinah International University, Pusat Perdagangan Salak 2, \\ No.18, Jalan 2/125e, Taman Desa Petaling, 57100 Kuala Lumpur, Malaysia.
}

\section{Article Info \\ Article history: \\ Received December 10, 2020 \\ Revised December 17, 2020 \\ Accepted December 21, 2020 \\ Published December 30, 2020}

\section{Keywords:}

Decision Making Information System Knowledge Management Railway Industry

Supply Chain

\begin{abstract}
Knowledge Management System (KMS) is a monitoring system that emphasizes the desired and actual performance of an industry. Aligning KMS to viably execute the Railway Industry methodology and supply chain operations utilizing legitimate knowledge management capabilities. Yet KMS controls the planning and priorities through action controls that emphasize on operational control level, result controls toward the strategic planning level, personnel controls on retaining the right operation with the right skills, and transaction control on the accurate and complete legal transactions for ensuring strategic management. Therefore, we have come up with a dynamic KMS for the Railway Supply Chain context that focuses on operational, tactical, and strategic perspectives on the information sources, value, analytics, and requirement for current and future drivers of an industry perspective. Moreover, this KMS aims to redesign the Information System by promoting a reductionist approach to problem-solving and best decisionmaking practices within an industry context.
\end{abstract}

\section{Corresponding Author:}

Mailasan Jayakrishnan,

Centre for Advanced Computing Technology,

Faculty of Information \& Communication Technology,

Universiti Teknikal Malaysia Melaka, Malaysia.

Email: m031620010@student.utem.edu.my

\section{INTRODUCTION}

Novel thoughts are basic if learning is to occur. Now and again they are made through glimmers of understanding or innovativeness, at different occasions they show up from outside the industry or through communication by Knowledge Management (KM) [1]. Whatever be the sources, these thoughts are the spark for industry progress [2]. Be that as it may, they cannot themselves make a learning organization. It has been found that industry has been effective in creating new knowledge or acquiring the same but all of them have one common thing but are strikingly less effective in applying the information to their exercises [3]. A conveying system or the everyday industry of an organization expects heads to come together to settle on aggregate decision making [4]. Moreover, it is to get choices made at the correct spot and to the correct quality, and that the industry is too moderate getting the aftereffects of the choice executed that can cause the issues.

Besides its failures to get choices made and ordered adequately that lead to advertising openings and the organization becomes unproductive where the customary way to deal with improving dynamic is imperfect. Thus, it is guaranteeing responsibility for decision-making, where the industry needs to understand what decisions being asked to make and decision-makers have the right information to base a decision [5]. Properly tailored decision-making will capture information for a wider context and enhance their capacity to respond to choices likewise. Knowledge Management System (KMS) can deliver this issue to make a genuine preferred position and make critical walks in conveying methodology for an industry context. Yet, KMS gives us oneof-a-kind bits of knowledge into how the industry is organized, overseen and heads lead through eliminating the executive's levels that beneficially affected the capacity of organizations to send data from one finish of the organization to the next with a more extensive dynamic process. Railway Industry (RI) has also responded to greater market complexity by emphasizing KMS and industry ability to make decisions that have oriented on people, process, and knowledge as presented in Figure 1. 


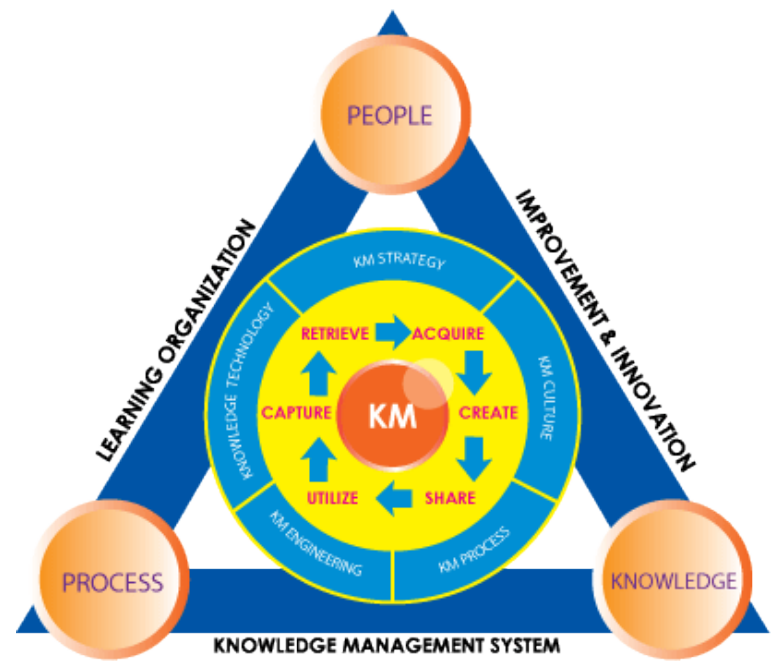

Figure 1. The Knowledge Management System

Based on Figure 1, KMS's emphasis on structure dependent on a general light-footed plan and set of guidelines is done and innovation is utilized to comprise an assortment of facilitated cycles and frameworks that serves a planning and decision-making process. The main concept of KMS is a technique and industrydriven movement that upholds the executives arranging and dynamic by giving composed perspectives on a whole industry. Moreover, it provides the industry an opportunity to experiment with the KMS so that they more readily understand the functionality and potential of the system as presented in Table 1 .

Table 1. The Knowledge Management System for Railway Industry Components

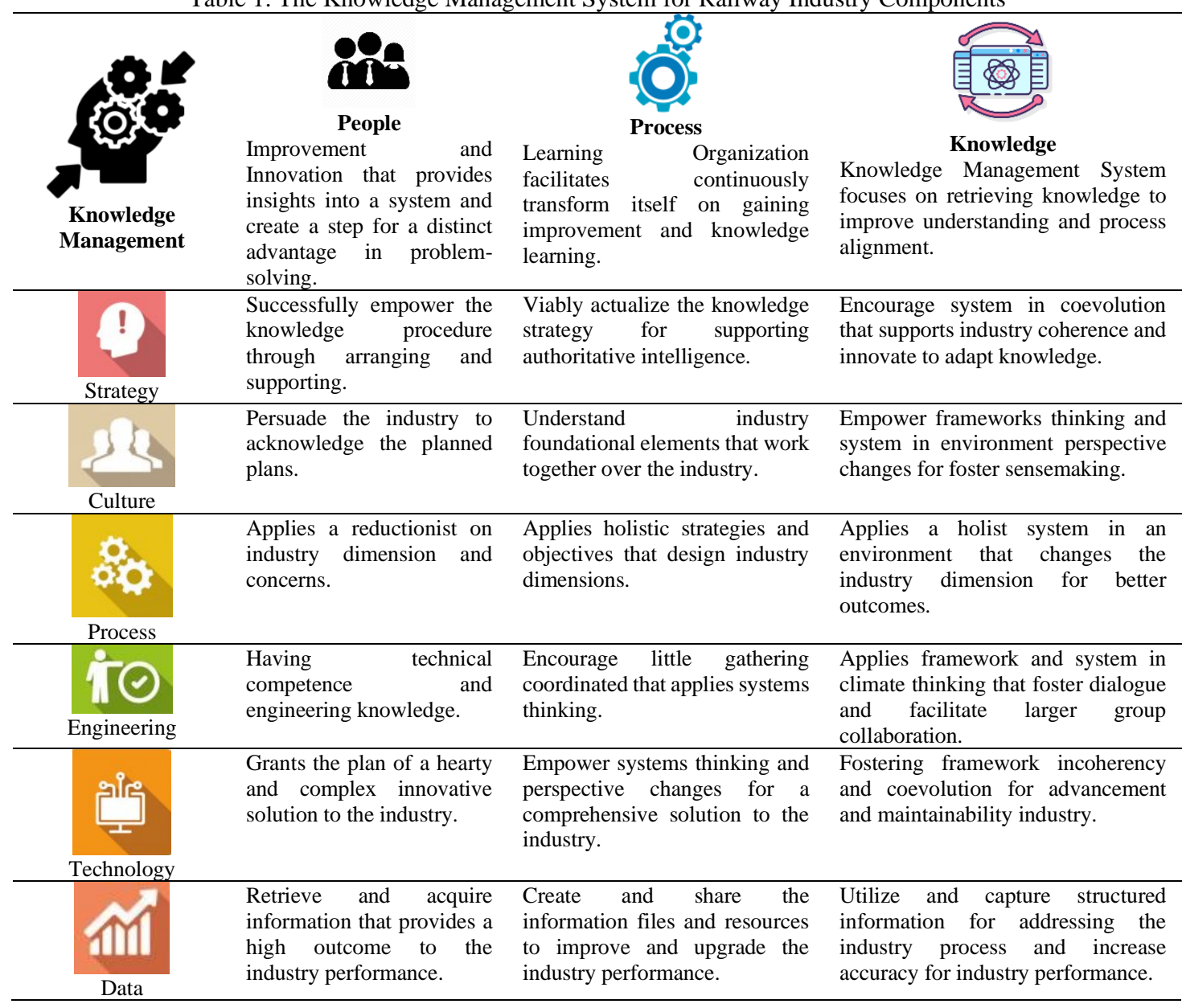


Based on Table 1, the KMS for RI components indicates the system that interrelated people, elements, and activities with the same outcomes. The KMS is a techno-economic system that transactions between the industry and works the general procedure for keeping an upper hand. Adjusting the industry and KM methodologies in a legitimate Information System (IS) capacities uphold the current and future current and future industry demands [6]. Yet KMS is the conversion of data into information, where industry able to analyses the information to gain insight and act as presented in Figure 2.

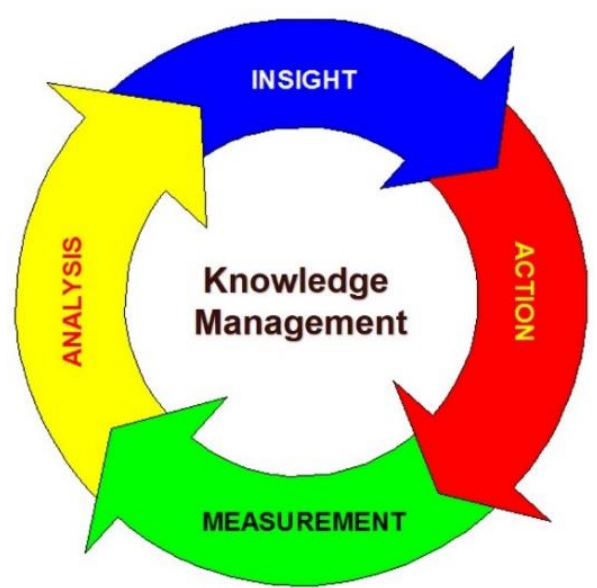

Figure 2. The Knowledge Management System Cycle

Based on Figure 2, the KMS cycle emphasis insight that shares the expectation of the industry, the action that creates a value for the industry performance, a measurement that emphasis the operational model of the industry going to use, and analysis that focuses on learning efforts of the industry outcomes. Moreover, the KMS cycle is an informed decision making as a prerequisite for success context that focuses on output and industry analysis requirements. Besides KMS cycle support RI choices by gathering, uniting and putting together information for announcing and investigation with apparatuses for performance and industry views. Moreover, the state of KM at present focuses on data complexity, process, and people that formulated a higher level. Thus, effectively implement the overall KM strategy by maximizing coherency between innovation and learning process will set an objective for the RI. Merging and matching information to perceived performance on the complexity and drive significant value for strong KM strategy. We also emphasize that KMS is an agile technology that implements cross-functional boundaries that involve many stakeholders for delivering a significant value outcome and offers a pragmatic way of delivering a high return in the short-term period for RI performance that ensures the industry objectives and goals are met.

\section{METHOD}

Constructing a system model for a Railway Industry (RI) supply chain is not direct, developing KM is not in every case simple. What makes the cycle significantly all the more testing is using KM to cope with RI change [7]. Constructing KM may need to layout the structure of the RI supply chain showing how its tiering and other operations work together. Before designing KM for the RI supply chain also needs a blueprint of how the Malaysia Transportation Industry (MTI) wants the RI supply chain to be [8]. Likewise, to utilize KM to manage with industrial alternate, KMS requires both as-is and to-be perspectives of the MTI to portray precisely or map how it works, to empower the disclosure of RI supply chain improvements opportunities, and to support the arranging and execution of progress activities that convey groundbreaking results. Without discerning the motivation for MTI and alternate, could fall flat or not expedient the ideal desires.

To perceive how KM could be utilized to arrive at a typical comprehension of the motivation, it is critical to see how KM is developed in a research field [9]. It seems that what constitutes KM depends on its intended use. This makes purpose, scope, and conceptually suggesting that each instance of KM is its truth. Hence it is important to consider KM as a continuum that covers everything from the technical to the knowledge level [10]. This research is viewed from an information and industry research perspective. The information focuses on the collection, classification, manipulation, retrieval, and distribution of information. It is a broad interdisciplinary field, among which management and model-based system development. Industry research focuses on interactions between people within the industry and gains insights into the industry. There are many factors concerning an industry. Industry research endeavors to comprehend and demonstrate these components. 
Like information, industry research looks to control, anticipate, and clarify. KMS is concerned with the theoretical foundations of models as well as the processes involved in the KM context of systems development. Within KMS, theories for KM are founded on a managerial approach. As contributions to the planning cycle, key things are industry systems and destinations. Railway supply chain reduced substantially and increase its holistic strategies that require many sub-strategies at the operational level. On the other hand, existing resources must be effectively and efficiently managed. It is depicted that strategic objectives are imperative to drive the outcomes as shown in Table 2.

Table 2. Strategic Objectives to Drive the Railway Supply Chain Outcomes.

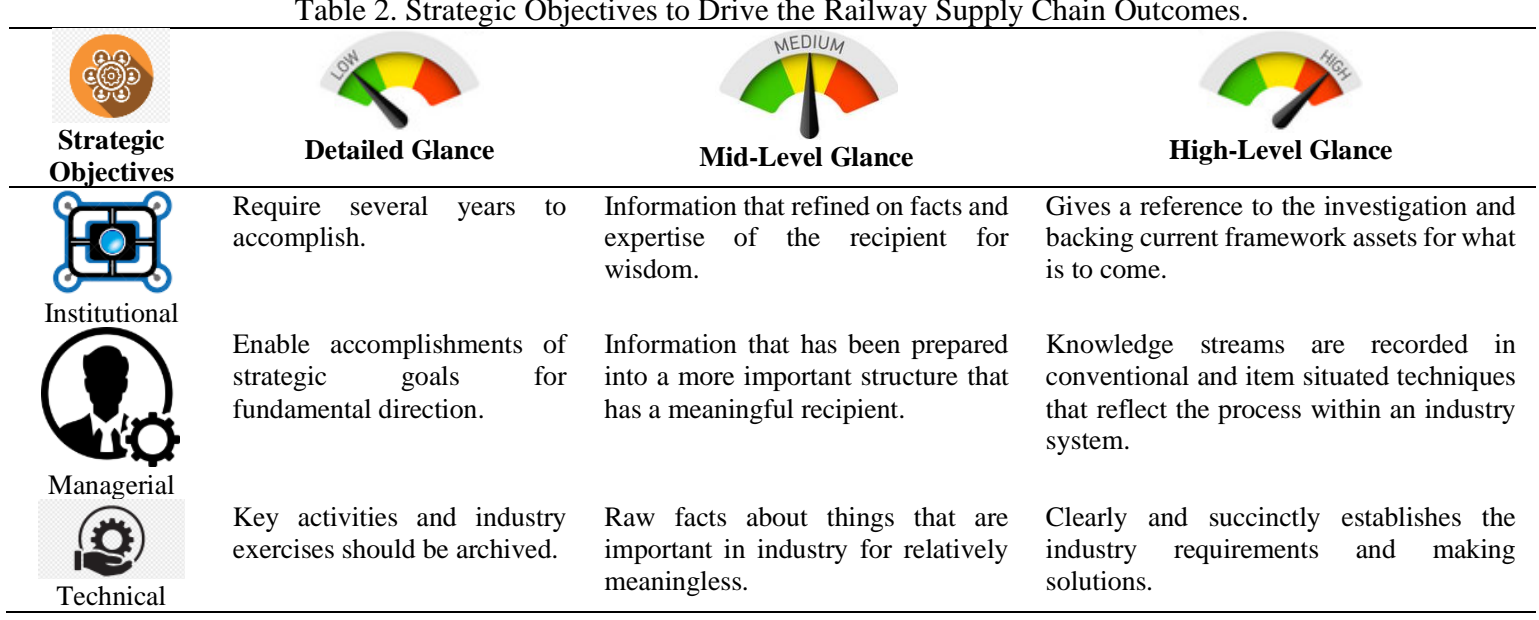

Based on Table 2, strategic objectives to drive the railway supply chain outcomes will be active in the operating as the to-be view of KMS and as-is view that emphasis on current KM resources. Nonetheless, it cannot be denied that there are critical enablers for those strategies to be successfully implemented. Advanced use of KMS in the context of optimizing technology to closely monitor and manage crucial enabler. Thus, it should strategic knowledge and innovation for the future that provides a sustainable solution through technological innovation that increases knowledge transfer to the industry and linkages maximizing KMS.

\section{RESULTS AND DISCUSSION}

The Knowledge Management System (KMS) connects operations in generating insights that help the Railway Industry (RI) to optimize their organization performance. It focuses on human development and enhancement of human performance for inter-relationship between people, industry, technology, and information environment that emphasize information landscape [11]. Information landscape focus on (1) social dimension information is created and disseminated, (2) historical dimension is linked with inserting information within the richness of the past and the constraints of the present, and (3) linguistic dimension comprises theoretical or practical preunderstanding. Thus, the system can be classified as (1) mechanistic system functions according to some predefined procedures and future behavior on the situation events that easier to control, (2) probabilistic system depends on the probability that needs a lot of control effort to be directed to these systems and (3) cybernetics system is an adaptive or self-regulating system that adapts to the environment for their survival.

Besides KMS needs to focus on the value proposition of the change management program and extending Knowledge Management (KM) awareness [12]. KM should continue to roll out and see strong linkages with info quality programs and establishing an operation stream for the industry [13]. Yet KMS integration of KM practices into planning and risk processes for retention and disposition directive in progress. Moreover, it should continue to refine and embed within existing processes of KM assessments and tailored views of the repository front end [14]. Simple analytics have been applied by the system to the supply chain data that reveals basic insights, and more sophisticated analytics for deeper insights as shown in Table 3. 
Table 3. Dynamic Knowledge Management System for Railway Supply Chain

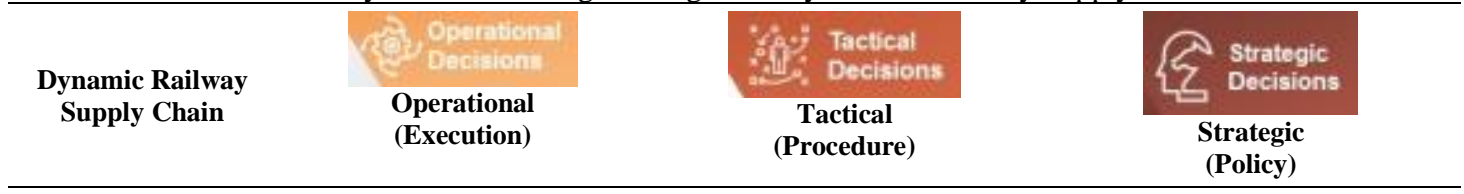

\begin{tabular}{|c|c|c|c|}
\hline & $\begin{array}{l}\text { External information on prices, } \\
\text { suppliers, and inventory. }\end{array}$ & $\begin{array}{l}\text { Operation information on } \\
\text { location, condition, and use. }\end{array}$ & $\begin{array}{l}\text { Industry information on assistance } \\
\text { narratives and guarantee status. }\end{array}$ \\
\hline \multicolumn{4}{|l|}{ Information Sources } \\
\hline Information Value & Basic insight that uses patterns. & $\begin{array}{l}\text { Information aggregated in } \\
\text { multiple formats for better value. }\end{array}$ & $\begin{array}{l}\text { Control and optimization by } \\
\text { knowledge overhauls that improve } \\
\text { execution. }\end{array}$ \\
\hline Information Analytics & $\begin{array}{l}\text { Descriptive focus on catch } \\
\text { items, condition, climate, and } \\
\text { activity. }\end{array}$ & $\begin{array}{l}\text { Diagnostic focuses on examining } \\
\text { the reasons for diminished item } \\
\text { execution or disappointment. }\end{array}$ & $\begin{array}{l}\text { Predictive focus on detecting } \\
\text { designs that sign approaching } \\
\text { occasions. } \\
\text { Prescriptive focus on identifying } \\
\text { breadth to revise results or right } \\
\text { issues. }\end{array}$ \\
\hline $\begin{array}{l}\text { Information } \\
\text { requirement }\end{array}$ & $\begin{array}{l}\text { Physical requirements focus on } \\
\text { information creation, use, and } \\
\text { information retrieval of an } \\
\text { industry. }\end{array}$ & $\begin{array}{l}\text { Semantic requirements focus on } \\
\text { information sharing, seeking, } \\
\text { problems, and activity of industry. }\end{array}$ & $\begin{array}{l}\text { Community requirements focus on } \\
\text { information transformation, digital } \\
\text { literacy, information practice, flow, } \\
\text { and behavior within an industry. }\end{array}$ \\
\hline
\end{tabular}

Based on Table 3, the dynamic KMS for Railway Supply Chain indicates the conceptualization of opportunities for interaction among industry communication. Dynamic KMS for railway supply chain focuses on organizational components of the information in a holistic perspective that is embedded in a particular context. Information should inform and guide the industry to reach decisions for situations and should support effective information behavior. Yet it improves the strategic decision-making process of the railway supply chain towards achieving better-strategized performances.

\section{CONCLUSION}

KMS enhance multiple intelligences for the railway supply chain in the future. The KM for strategic decisionmaking process would help the industry learning atmosphere for achieving its intended goals. Holistic planning of the information within an industry will enable the organization to interpret the changes in the RI and choose the right strategy to respond. The KM revolution may achieve RI's aim to effectively implement the innovation and transformation explores especially from an organizational learning perspective. This transformation has aided improvement on the standard of RI that resulted empowered the organization's decision-making process. Yet it also facilitates us in the following degree of Predictive knowledge "what might occur if" and Prescriptive knowledge "what should be done" in catching, recording, and depicting the usage and activity of vital management just as ideas and explanations behind such checking and controlling instrument and cycle in the unique situation and complexities of visual analytics.

Moreover, the science behind the technology is solving technical problems with the technology that emphasis the engineering of the components that make up the systems. Thus, the implementation side of the industry problems is creating a system to collect, manipulate, store, and retrieve information that utilizes within the RI infrastructure. Besides the result of the information system, should uses the KMS to conduct industry solution on comprised information technology and focus on understanding problems from the perspective of the organization involved and applying information and other technologies as needed. We recommend initially configure and customize the software so that it enables RI to change their working practices and work with the system for better outcome performance.

\section{ACKNOWLEDGEMENTS}

The authors wanted to thank the editor and reviewers for their positive comments and suggestions for correcting the nature of this article.

\section{REFERENCES}

[1] Z. Yao, Z. Yang, G. J. Fisher, C. Ma, and E. (Er) Fang, "Knowledge complementarity, knowledge absorption effectiveness, and new product performance: The exploration of international joint ventures in China," Int. Bus. Rev., vol. 22, no. 1, pp. 216-227, Feb. 2013.

[2] M. A. Jayakrishnan, A. K. Bin Mohamad, and M. B. M. Yusof, "Integrating the Features of Knowledge Management (KM) and Business Intelligence (BI) for Developing Organizational Performance Framework-A Diagnostics Dashboard," Adv. Sci. Lett., vol. 24, no. 3, pp. 1795-1799, 2018. 
[3] C. E. Connelly, D. Zweig, J. Webster, and J. P. Trougakos, "Knowledge hiding in organizations," J. Organ. Behav., vol. 33, no. 1, pp. 64-88, Jan. 2012.

[4] M. Jayakrishnan, "Analysis Of Socio-Technical Factors In Business Intelligence Framework Case Study Of Higher Learning Institution,” Universiti Teknikal Malaysia Melaka, 2018.

[5] S. P. Turner, The social theory of practices: tradition, tacit knowledge and presuppositions. John Wiley \& Sons., 2018.

[6] P. Soto-Acosta and J.-G. Cegarra-Navarro, "New ICTs for Knowledge Management in Organizations," J. Knowl. Manag., vol. 20, no. 3, pp. 417-422, May 2016.

[7] M. Jayakrishnan, A. K. Mohamad, and M. M. Yusof, "Digitalization Railway Supply Chain 4.0: Enterprise Architecture Perspective,” Int. J. Adv. Trends Comput. Sci. Eng., vol. 9, no. 5, pp. 9056-9063, 2020.

[8] W. Y. Ng, "Adoption of Building Information Modelling (BIM) on Railway Transportation Project in Malaysia," UTAR, 2018.

[9] B. Afsar, M. Masood, and W. A. Umrani, "The role of job crafting and knowledge sharing on the effect of transformational leadership on innovative work behavior," Pers. Rev., vol. 48, no. 5, pp. 1186-1208, Aug. 2019.

[10] I. Bleiklie, The new public management and the pursuit of knowledge. LOS Senter, 1994.

[11] M. Jayakrishnan, A. K. Mohamad, and A. Abdullah, "A Systematic Literature Review in Enterprise Architecture for Railway Supply Chain of Malaysia Transportation Industry,” Int. J. Eng. Res. Technol., vol. 12, no. 12, pp. 2473-2478, 2019.

[12] G. D. Jenkins and N. Gupta, "The payoffs of paying for knowledge," Natl. Product. Rev., vol. 4, no. 2, pp. 121$130,1985$.

[13] K. A. Al-Busaidi and L. Olfman, "Knowledge sharing through inter-organizational knowledge sharing systems," VINE J. Inf. Knowl. Manag. Syst., vol. 47, no. 1, pp. 110-136, Feb. 2017.

[14] M. Jayakrishnan, A. K. Mohamad, and M. M. Yusof, "Understanding Big Data Analytics ( BDA ) and Business Intelligence ( BI ) Towards Establishing Organizational Performance Diagnostics Framework,” Int. J. Recent Technol. Eng., vol. 8, no. 1, pp. 128-132, 2019. 